\title{
Cross-Country and Gender Differences in Factors Associated with Population-Level Declines in Adolescent Life Satisfaction
}

\author{
Jose Marquez ${ }^{1}\left(\mathbb{D} \cdot\right.$ Joanna Inchley $^{2}\left(\mathbb{1} \cdot\right.$ Emily Long $^{2}(\mathbb{0}$
}

Accepted: 9 February 2022 /Published online: 21 February 2022

(c) The Author(s) 2022

\begin{abstract}
Adolescent subjective well-being, including life satisfaction, has shown declines at national level across many countries in recent years. Although several possible explanatory factors have been identified, there is a lack of research on whether these may be similar or different across countries. Using data on 15-year-old adolescents from the Programme for International Student Assessment study in Scotland, England, Wales, Northern Ireland, the United States, Japan, Ireland and France in 2015 and 2018, we find that changes in school well-being and, to a lesser extent, the use of Information and Communication Technologies and material well-being were associated with observed declines in life satisfaction. Although there are similarities across some countries, cross-country differences in factors associated with decreasing life satisfaction emerged, notably between Western nations and Japan, with some gender differences also evident.
\end{abstract}

Keywords Adolescence $\cdot$ Subjective well-being $\cdot$ Life satisfaction $\cdot$ School wellbeing $\cdot$ Information and communications technology $\cdot$ Videogames

Jose Marquez

jmm267@cam.ac.uk

Joanna Inchley

Joanna.Inchley@glasgow.ac.uk

Emily Long

Emily.Long@glasgow.ac.uk

1 University of Cambridge, 184 Hills Rd, Cambridge CB2 8PQ, UK

2 University of Glasgow, 99 Berkeley Square, Glasgow G3 7HR, UK 


\section{Introduction}

There is an increasing body of research reporting population-level declines in subjective well-being and an increases in mental health problems among children and young people - particularly among females- observed over the last two decades in multiple countries (Curtin et al., 2016; Kim \& Hagquist, 2018; Marquez \& Long, 2020; Mishina et al., 2018; Mojtabai et al., 2016; The Children's Society, 2020; Twenge et al., 2017, 2018). The present study investigates factors associated with population-level declines in 15-year-old adolescents' subjective well-being -more specifically, overall life satisfaction (LS)- with a focus on differences across gender and countries.

\subsection{Defining Subjective Well-Being and Life Satisfaction}

Subjective well-being is often conceptualised in a Tripartite model that includes an affective component (including the experience of both positive and negative affects, moods and feelings) and a cognitive component -i.e., satisfaction with different aspects of life and with life as a whole (LS)- (Arthaud-Day et al., 2005; Diener et al., 2002; Metler \& Busseri, 2017). In this study, we focus on LS, which is the most common indicator used by researchers to study subjective well-being in adolescents (Proctor et al., 2009).

Noting these conceptual differences is important because, although subjective well-being has been deteriorating in some countries, research indicates that differences between subjective well-being domains can be substantial (The Children's Society, 2020). Similarly, not only are young people increasingly reporting lower subjective well-being in many parts of the world, but they are also reporting more mental health problems. Although research indicates that subjective well-being and mental health are different constructs, with different correlates and may follow different trajectories over the life course (Kinderman et al., 2015; Patalay \& Fitzsimons, 2016, 2018; Westerhof \& Keyes, 2010), they are intrinsically related. Understanding trends and factors associated with declines in these different but related outcomes can help understand what may be driving declines in adolescents' LS. The next section presents an overview of research studying a deterioration in subjective well-being (including LS) and positive mental health in young people.

\subsection{Negative Trends in Population Levels of Subjective Well-Being and Positive Mental Health in Young People: The Moderating Role of Gender}

Several studies in the United Kingdom (UK) have reported on declines in young people's subjective well-being and increases in symptoms of poor mental health in recent years (Earle, 2016; Frith, 2016; Patalay \& Fitzsimons, 2017). McManus et al. (2019) found that rates of non-suicidal self-harm - which is increasingly being reported as a way of coping with unpleasant feelings of anger, tension, anxiety, or depression - tripled in England between 2000 and 2014, particularly 
among young women aged 16-24. Similarly, The Good Childhood Report 2020 (The Children's Society, 2020) found that children's subjective well-being in the UK has been falling for almost a decade. In the United States (US), multiple studies have reported an increase in adolescent and young people's depression, anxiety, loneliness, nonfatal self-inflicted injury and, suicidal ideations, suicide attempt, suicide, and a decline in subjective well-being around the period 20052018 (Curtin et al., 2016; Goodwin et al., 2020; Mercado et al., 2017; Mojtabai et al., 2016; Mojtabai \& Olfson, 2020; Twenge, 2020; Twenge et al., 2017, 2018). Again, gender differences emerge as these trends were particularly evident among girls. Similar findings have also been found in Germany, Sweden, Finland, Norway and New Zealand (Bor et al., 2014; Brailovskaia \& Margraf, 2020; Brann et al., 2017; Fleming et al., 2014; Kim \& Hagquist, 2018; Mishina et al., 2018; Potrebny et al., 2017, 2019).

The number of studies exploring factors associated with these negative trends in subjective well-being and mental health outcomes has grown in recent years. This research highlights the potential role played by a myriad of factors, notably the increasing use of Information and Communication Technologies (ICT), a deterioration of socio-economic circumstances and school well-being. For example, studies in the US have found that psychological well-being (broadly defined in these studies as including self-esteem, life satisfaction, happiness, etc.) was negatively correlated with time spent on electronic communications and screens (e.g. the internet, social media, texting, gaming), and positively correlated with spending time on non-screen activities such as in-person social interaction, sports/exercise, and homework. Similarly, mental health problems (depression, self-harm, suicide) were found to be positively correlated with screen time (Twenge, 2020; Twenge et al., 2017, 2018). Anxiety related to social media use seems to be an important factor potentially driving these negative trends (Bell et al., 2019). However, more recent work suggests that excessive or problematic social media use is associated with poorer subjective well-being and mental health, rather than time spent on electronic media per se (Boer et al., 2020). Beyond ICT and social media use, a variety of other factors have been identified, including the normalization of mental distress and self-harm, anxiety related to future orientation, and academic pressure (Bell et al., 2019). With regard to socio-economic circumstances, evidence suggests that poverty and austerity play an important role in adolescent mental health and subjective well-being (Bell et al., 2019; Gross-Manos \& Bradshaw, 2021; Holstein et al., 2020), although research among adolescents in the US found no correlation between deteriorations in psychological well-being and mental health and cyclical economic indicators such as unemployment (Twenge et al., 2017, 2018). In relation to the school environment, research in the UK has found that school is the domain where children's satisfaction declined the most in recent years. Specifically, while there has been no variation in satisfaction with family in the last decade, there has been a sustained decline in satisfaction with friends since 2009, and a decline in satisfaction with appearance, schoolwork and school since 2015. There have also been sustained gender differences in satisfaction with appearances (higher among males) and schoolwork (higher among females) (The Children's Society, 2020). 


\subsection{Cross-Country Variation in Population-Level Declines in Adolescents' Subjective Wellbeing and Factors Associated with this Decline}

Most of the research exploring this deterioration in adolescents' subjective wellbeing, and the factors associated with these negative trends, focus on Western nations, leading to a lack of research exploring whether explanatory factors may be similar or different across countries. Differences across countries in the factors associated with declines in subjective well-being are likely to exist. The main reason is that international comparative research studying levels and correlates of children's subjective well-being has found some similarities across nations -e.g. bullying, school anxiety and parental support have been identified as 'universal' factors associated with adolescents' subjective well-being (Marquez \& Main, 2020)- but also some differences across distinct socio-cultural settings (Dinisman \& Ben-Arieh, 2016; Klocke et al., 2014; Marquez \& Main, 2020; Rees \& Main, 2015). For example, compared to Western nations, Eastern Asian individuals tend to report lower levels of subjective well-being. Another example is bullying, which seems to be a better predictor of subjective well-being in rich than in poor countries (Bradshaw et al., 2017; Savahl et al., 2019). Some of these differences may be mainly due to linguistic and/or cultural considerations which may affect participants' responses in questionnaires (Bradshaw, 2015; Leu et al., 2011; Lu \& Gilmour, 2004), but in other cases, this may be largely explained by children having different life experiences in distinct parts of the world.

A few recent international comparative studies have explored declining levels of subjective well-being. For example, Marquez and Long (2020) identified a global decline in the LS of 15-year-old adolescents during the period 2015-2018, observed in 39 out of 46 countries studied. Importantly, despite significant cross-country variation, the study found that this decline was particularly accentuated among girls, as well as among adolescents of higher socio-economic status. This evidence suggests that although declining LS at the population level seems to be a global phenomenon, differences across countries and groups can be substantial.

However, scarce research has examined variation in the factors associated with these negative trends from a comparative perspective. One exception is a recent cross-national study using data from 36 countries, aimed at assessing changes in the mental well-being of adolescents aged 11-15 in the period 2002-2018, and the extent to which these were associated with increasing levels of school pressure (Cosma et al., 2020). The authors found a small but significant increase in psychosomatic health complaints in most countries but no overall change in LS, which declined in 13 countries and increased in another 13. This study also revealed a small overall increase in perceived school pressure, which explained a small proportion of the increase in psychosomatic health complaints overall, although differences across countries were substantial.

All in all, despite the increasing body of research studying declining levels of children and young people's subjective well-being, and the factors associated with this decline, there is still little international comparative research in this area. As noted above, previous research has widely reported on socio-cultural differences in subjective well-being (Bradley \& Corwyn, 2004; Bradshaw, 2015; Casas et al., 
2012, 2014; Leu et al., 2011; Lu \& Gilmour, 2004) and, therefore, the aim of the present study is to examine factors associated with declines in adolescent LS, and whether these may be similar or different across countries. In addition, given evidence that females experienced more drastic declines in LS in recent years (Marquez \& Long, 2020; McManus et al., 2019; The Children's Society, 2020; Twenge, 2020; Twenge et al., 2017, 2018), the study also explores if risk factors for declines in LS differ across gender. The study focuses on three domains that -as discussed abovehave previously been identified as playing an important role in relation to these negative trends: ICT use, socio-economic circumstances (material well-being) and school well-being. Specifically, we examine the following research question: Do factors associated with declining levels of adolescents' LS, specifically ICT use, material well-being, and school well-being, differ across countries and gender? In view of the literature discussed above, we hypothesize that -although some cross-country similarities can be expected, particularly in Anglo-Saxon and English speaking countries- the association between these factors and declining LS differs across gender and nations -especially between those that are more socio-culturally different. We assess this by investigating cross-country differences in factors associated with the cohort gap in 15-year-old adolescents' LS (i.e. the difference in LS between the 2015 and 2018 cohorts) and how this varies by gender.

\section{Methods and Data}

\subsection{Participants}

We used data from the 2015 and 2018 waves of the Programme for International Students Assessment (PISA) study (OECD, 2017a, 2019a). This is a worldwide study by the Organisation for Economic Co-operation and Development (OECD) conducted every 3 years in member and non-member countries and economies. PISA focuses on 15-year-old students' academic performance and also collects information on education policy and practice and the broader well-being of students. The total sample size is 30,541 and includes a representative sample of 15-year-old students in Scotland, England, Wales, Northern Ireland, Japan, United States, Ireland and France.

\subsection{Measures}

\subsubsection{Outcome Variable (Life Satisfaction) and Categories of Interest (Cohort, Country and Gender)}

LS was measured using Cantril's ladder (Cantril, 1965). Participants were asked to rate their LS, ranging from 0 (not at all satisfied) to 10 (completely satisfied). Differences across countries were examined by using PISA's variables Country and Region. We also used a dichotomous variable for cohort (2015 or 2018) and a dichotomous variable for gender (male or female). 


\subsubsection{Explanatory Variables: School Well-Being, Material Well-Being and ICT Use}

Three groups of variables representing potential explanatory factors were included in these analyses: school well-being, material well-being and ICT use.

In the school well-being domain, three subdomains (15 items, Cronbach's Alpha ranging from 0.79 in France to 086 in Scotland) were considered. This includes self-reports of belonging at school (6 items, Cronbach's Alpha ranging from 0.70 in France to 0.85 in the United States), parental support in relation to school (3 items, Cronbach's Alpha ranging from 0.76 in France to 0.84 in Wales), and bullying (6 items, Cronbach's Alpha ranging from 0.81 in Japan to 0.86 in Scotland). The items included in each subdomain are enumerated in Appendix 1. For each school wellbeing subdomain, we derived a scale summing up scores in each of the items considered and standardised these in each country so that 0 indicates the mean score considering both cohorts together and 1 indicates the standard deviation.

As to material well-being, PISA includes three material well-being sub-scales (family wealth (13 items, Cronbach's Alpha ranging from 0.59 in Northern Ireland to 0.70 in France), home educational resources (8 items; Cronbach's Alpha ranging from 0.44 in France to 0.55 in the United States) and cultural possessions in the household ( 8 items, Cronbach's Alpha ranging from 0.63 in Ireland to 0.69 in France) and a combined material well-being scale (household possessions; 29 items, Cronbach's Alpha ranging from 0.70 in Scotland to 0.79 in the United States) which is derived from all the items included in the three scales. The specific items included in each of the material well-being scales are enumerated in Table A1.1 in Appendix 1. Again, we standardised these scales in each country.

Finally, ICT use was assessed using first, a group of variables that aim to measure the time spent using ICT at school in general -e.g. browsing the Internet for schoolwork, playing simulations at school, etc.; (11 items, Cronbach's Alpha ranging from 0.76 in England to 0.80 in France). Second, a group of variables that intend to measure how often students use ICT outside the school for schoolwork (11 items, Cronbach's Alpha ranging from 0.84 in Japan to 0.89 in Ireland), including variables such as browsing the Internet to follow up lessons, using email for communication with other students about schoolwork, etc. And third, a group of variables that aim to measure how often the student uses ICT at home for leisure (e.g. playing collaborative online games using social networks (e.g. Facebook, MySpace), etc.; 10 items, Cronbach's Alpha ranging from 0.84 in Japan to 0.90 in France)). The complete list of items in each group of ICT variables is detailed in Table A1.2 in Appendix 1. The Cronbach's Alpha of all the 32 ICT items ranges from 0.87 in Japan to 0.92 in France). We standardised each of the ICT use scales in each country.

\subsection{Analytical Procedure}

To compare changes over time, we used a dichotomous cohort variable indicating whether the respondent participated in the PISA study in 2015 or in 2018, and differences by gender were studied using a dichotomous gender variable. Analyses 
were conducted separately for girls and boys in the eight countries which experienced the most substantial decline in LS between 2015 and 2018 (Marquez \& Long, 2020): Scotland, England, Wales, Northern Ireland, Japan, United States, Ireland and France. These are the countries where LS declined on average by at least 0.60 points in the 0 to 10 points scale or where the proportion of students reporting low LS (i.e. 5 points or less on this scale) increased by at least $40 \%$. On the difficult task of deciding on these cut-off points, we aimed to strike a balance between focusing on those countries more at risk (i.e. those with more concerning trends in terms of mean LS or the proportion of students reporting low LS, or both) and achieving a minimum level of linguistic and cultural diversity while ensuring that the analysis did not become too complex due to including too many countries. We concluded that these are the cut-off points that better distinguish those most-at-risk countries from the rest, and, overall, seem the most adequate to strike this balance as described above. Thus, in sum, we focused specifically on these 8 countries rather than expanding to additional countries available in the PISA dataset, in order to provide a concise, and targeted, analysis of LS in high-risk countries, including at least one Eastern Asian nation.

First, we estimated mean levels of LS and changes in mean levels of LS for girls and boys in each country. Changes were estimated using linear regression analysis with LS as the outcome variable and the binary variable 'cohort' $(0=$ ' 2015 ', $1=$ '2018') as the predictor variable. Then, for each potential explanatory factor considered and for each group of interest (i.e. boys and girls in each country), first, we studied changes in these variables (scales and individual items) between 2015 and 2018 using linear regression analysis again in the same way, with each specific factor as the outcome variable and the binary variable 'cohort' as the predictor variable. And second, we studied to what extent changes in these factors were associated with the decline in LS for each group of interest. To do this, we conducted a Blinder-Oaxaca analysis (Blinder, 1973; Oaxaca, 1973). This method was originally developed to investigate different labour market outcomes across groups (e.g. men and women, different race or ethnic groups, etc.) but, more generally, it can be used to study group differences in outcomes, including differences across two distinct cohorts or generations (e.g. Etezady et al., 2021).

The Blinder-Oaxaca decomposition method was used to decompose the cohort gap in LS in view of (1) a series of selected explanatory variables (called endowments), (2) unexplained effects and (3) the interaction between the two. In the tables, we report only the endowment effects estimates as these are the estimates relevant to answer our research question. This term indicates the mean change in the level of the dependent variable (LS) of one group (2015 cohort) if this group had the values of the explanatory variables of the other group (2018 cohort) while holding its coefficients constant. Thus, these estimates indicate the relative importance of the explanatory variable(s) (i.e. each of the factors or groups of factors considered) when it comes to understanding the cohort gap in LS and whether its contribution to this gap was positive (i.e. potentially helping increase the cohort gap in LS) or negative (i.e. potentially helping decrease the cohort gap in LS). It must be noted that this analysis does not allow to infer causality, but indicates how changes in the explanatory factors studied are associated with changes in LS. We report the endowment 
effect estimates in absolute terms in Tables A3.1 to A3.7 in Appendix 3 and relative terms (i.e. as a proportion of the cohort gap in LS) in the main text in Tables 2 to 8 below. A more detailed explanation of how to interpret the results of this analysis is provided in Appendix 3. Finally, in all the analyses conducted, we apply final student weights to account for PISA's complex survey design. For the indices studied, a Cronbach's Alpha of 0.70 or above is considered to be acceptable. The analysis was conducted using Stata 15 (StataCorp., 2017).

\section{Results}

\subsection{Changes in Students' Life Satisfaction between 2015 and 2018}

Table 1 shows changes in students' LS between 2015 and 2018. In all countries but Japan, girls reported lower LS than boys on average. Likewise, between 2015 and 2018, the decline in students' LS was greater among girls than among boys in most countries, with a few exceptions -notably Scotland.

\subsection{Changes in School Well-Being and Associations with Declining Life Satisfaction}

Table 2 shows changes in school well-being between 2015 and 2018 in three subdomains (sense of belonging at school, feeling supported by parents in relation to school and the frequency of being bullied) and how these changes were associated with declining levels in LS. More detailed information by country, gender and item is provided in Tables A2.1 to A2.3 in Appendix 2 and Tables A3.1. to A3.3 in Appendix 3.

Table 1 Change in students' life satisfaction between 2015 and 2018, by gender and country

\begin{tabular}{|c|c|c|c|c|c|c|c|c|}
\hline & \multicolumn{2}{|l|}{2015} & \multicolumn{2}{|l|}{2018} & \multicolumn{4}{|l|}{ Change } \\
\hline & \multirow[t]{2}{*}{ Girls } & \multirow[t]{2}{*}{ Boys } & \multirow[t]{2}{*}{ Girls } & \multirow[t]{2}{*}{ Boys } & \multicolumn{2}{|l|}{ Girls } & \multicolumn{2}{|l|}{ Boys } \\
\hline & & & & & $\mathrm{B}$ & S.E. & B & S.E. \\
\hline England & 6.61 & 7.26 & 5.70 & 6.59 & $-0.91 * * *$ & 0.08 & $-0.68 * * *$ & 0.07 \\
\hline Scotland & 6.73 & 7.60 & 5.96 & 6.56 & $-0.76^{* * * *}$ & 0.10 & $-1.04 * * *$ & 0.09 \\
\hline Japan & 6.86 & 6.74 & 6.18 & 6.18 & $-0.68 * * *$ & 0.07 & $-0.56^{* * *} *$ & 0.07 \\
\hline Northern Ireland & 6.94 & 7.54 & 6.27 & 6.90 & $-0.67 * * *$ & 0.12 & $-0.64 * * *$ & 0.11 \\
\hline Wales & 6.74 & 7.52 & 6.07 & 6.84 & $-0.67 * * *$ & 0.11 & $-0.68 * * *$ & 0.11 \\
\hline United States & 7.06 & 7.66 & 6.47 & 7.03 & $-0.59 * * *$ & 0.06 & $-0.63 * * *$ & 0.08 \\
\hline Ireland & 7.02 & 7.58 & 6.45 & 7.02 & $-0.57 * * *$ & 0.07 & $-0.56^{* * *} *$ & 0.07 \\
\hline France & 7.41 & 7.86 & 6.93 & 7.44 & $-0.47 * * *$ & 0.06 & $-0.42 * * *$ & 0.05 \\
\hline
\end{tabular}

Notes: countries are ordered from greater to smaller change in mean life satisfaction among girls in the period 2015-2018

$* p<.05, * * p<.01$, and $* * * p<.001$ 


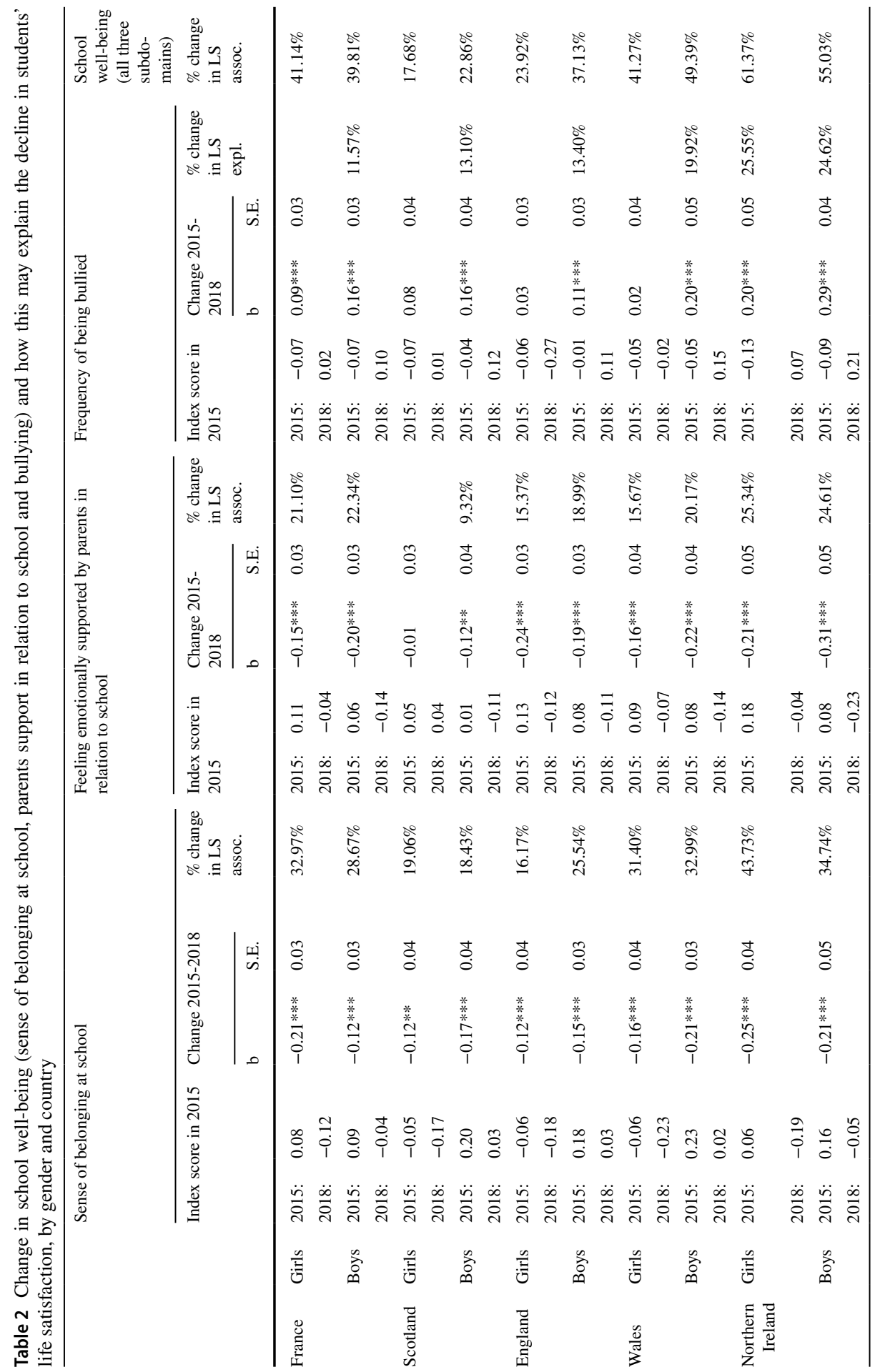




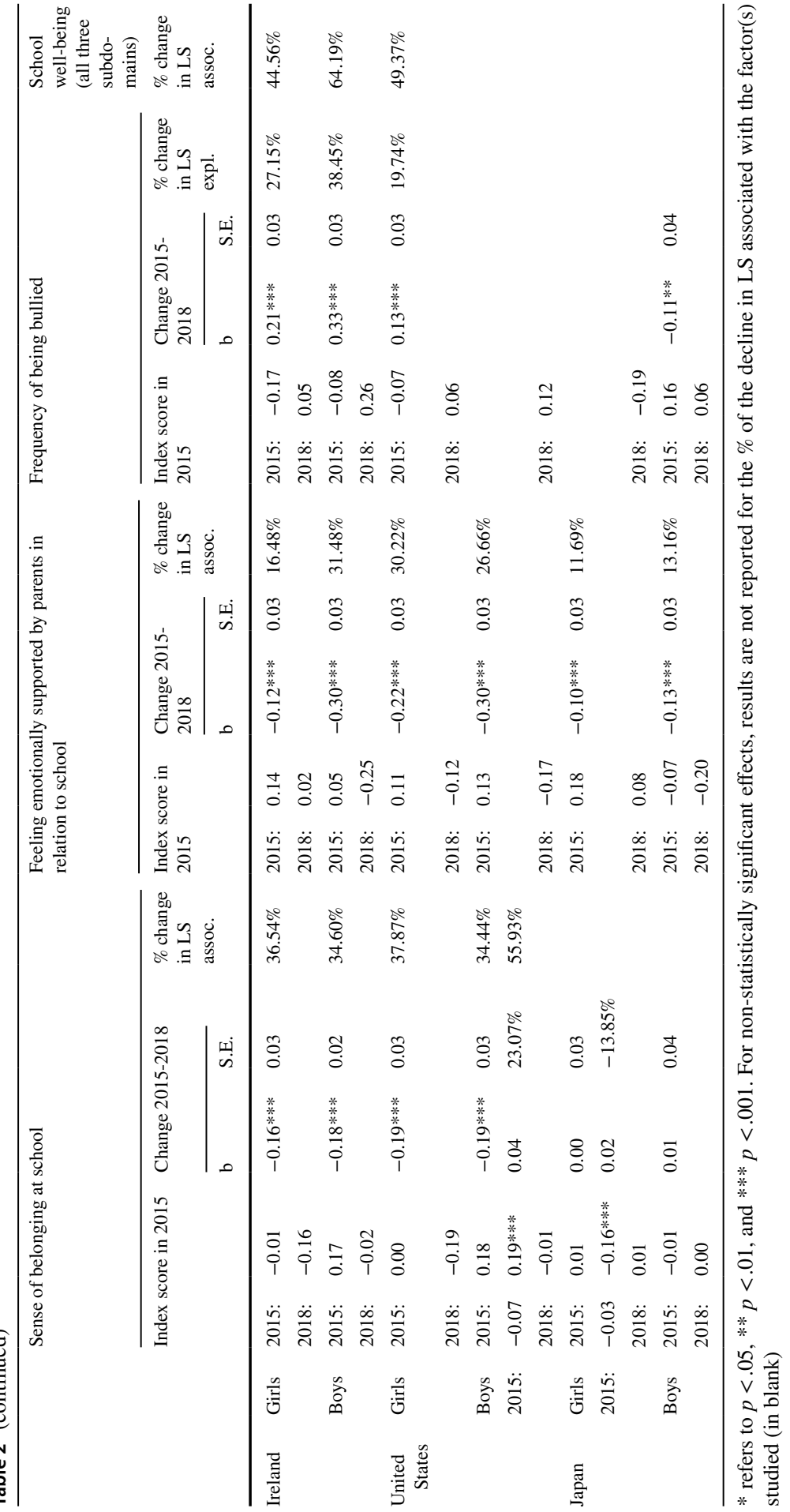




\subsubsection{Levels of School Well-Being across Gender and Countries}

Results in Table 2 show that, across countries, overall, students' sense of belonging at school was more positive among boys than girls, with the main exception of Japan where results were more mixed. Overall, boys reported lower parental support and higher levels of bullying than girls, although gender differences were smaller than for sense of belonging.

\subsubsection{Changes in School Well-Being between 2015 and 2018 across Gender and Countries}

Between 2015 and 2018, sense of belonging decreased for both gender groups in all countries, but changes were smaller in Japan. Parental support in relation to school decreased for boys and girls in all countries and this decrease was more accentuated among boys. There was also a moderate increase in the frequency of being bullied -particularly for some forms of bullying- which was greater among boys. In particular, 'Other students made fun of me' showed the most marked increases over time, although differences across countries were substantial (see Table A2.3 in Appendix 2).

\subsubsection{Association between Changes in School Well-Being and Declining LS across Gender and Countries}

In all countries except Japan, a substantial part of the cohort gap in LS was related to the deterioration in sense of belonging at school -relative endowment effects (i.e. endowment effects expressed as a proportion of the cohort gap in LS) ranging between $16.17 \%$ and $43.73 \%$. However, there were differences by country, gender and, as indicated in Tables A2.1 to A2.3 in Appendix 3, also by item. For example, across countries, the proportion of the cohort gap in LS related to increases in feeling left out, like an outsider and lonely was greater than for other sense of belonging items (see Table A2.1 in Appendix 2). Similarly, in all the countries, except for girls in Scotland, a substantial proportion of the cohort gap in LS was related to the deterioration in parental support in relation to school (relative endowment effects ranging between $11.69 \%$ and $30.22 \%$ among girls and $9.32 \%$ and $31.48 \%$ among boys). Again, there were differences by country and gender. Finally, a large part of the cohort gap was also related to increases in the incidence of bullying (relative endowment effects ranging between $19.74 \%$ and $27.15 \%$ among girls and $11.57 \%$ and $38.45 \%$ among boys) in all the countries except Japan, although in France, Scotland, England, and Wales this was significant for boys only. In Japan, the endowment estimates for girls was negative, meaning that there was a decline in LS despite the fact that the 2018 cohort of girls in Japan had less negative experiences of bullying than the 2015 cohort.

Finally, when considering the three subdomains of school well-being together, the proportion of the cohort gap in LS related to changes in students' (combined) 
experiences at school was substantial (relative endowment effects ranging between $17.68 \%$ and $61.37 \%$ among girls and $22.86 \%$ and $64.19 \%$ among boys) in all the countries but Japan.

\subsection{Changes in Material Well-Being and Associations with Declining Life Satisfaction}

Table 3 shows changes in students' material well-being between 2015 and 2018 and how these changes were associated with declining levels in LS. Detailed results of the Blinder-Oaxaca analysis by gender and country for each material well-being scale are presented in Table A3.5 in Appendix 3.

\subsubsection{Levels of Material Well-Being across Gender and Countries}

Material well-being in the educational and cultural subdomains appeared to be greater among girls than among boys. This was not observed in the family wealth subdomain, which considers more generic items (i.e. not so related to education), where results were more mixed. For the combined material well-being scale (household possessions, which includes all the items considered in the three material wellbeing scales), students' material well-being was slightly greater among girls overall.

\subsubsection{Changes in Material Well-Being between 2015 and 2018 across Gender and Countries}

Between 2015 and 2018, there was a decline in material well-being, with the exception of France and the US. This decline was more accentuated in the family wealth subdomain, and was particularly great in Japan. Moreover, evidence of gender differences in this decline in material well-being was mixed and it differed across countries and the three subdomains. For the combined material well-being scale (household possessions), material well-being decreased in Japan and Wales for both genders and in Ireland and Northern Ireland for boys only. Nonetheless, in most cases -except Japan- these changes were small.

\subsubsection{Association between Changes in Material Well-Being and Declining LS across Gender and Countries}

Changes in material well-being in the educational and cultural subdomains were rarely associated with declining levels in LS, but changes in the family wealth subdomain were associated with declining LS in Japan for boys (relative endowment effects of $10.15 \%$ ), Northern Ireland for girls (7.38\%), and both girls and boys in Wales $(10.10 \%$ and $4.86 \%$ ) and England (5.88\% and $8.87 \%$ ). In a few cases (notably in Japan in the educational subdomain for both girls and boys), endowment effects were negative, meaning that the decline in LS occurred despite the fact that material well-being improved between 2015 and 2018. For the combined material well-being scale (household possessions), only in a few cases -for girls in Wales (8.56\%) and 


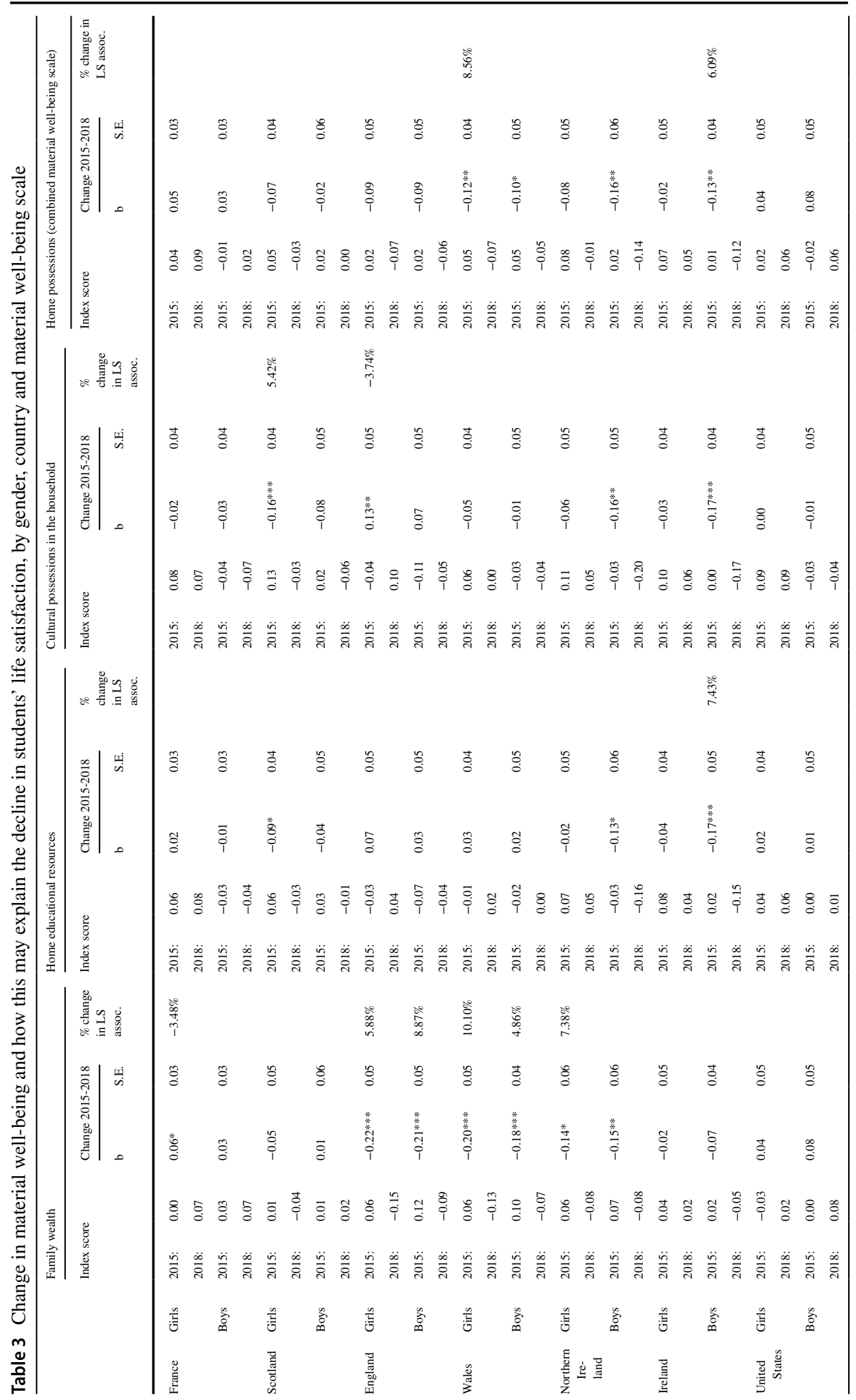




$$
\text { II }
$$


boys in Ireland (6.09\%) and Japan (6.58\%)- changes were associated with declining levels in LS (see Table 2).

\subsection{Changes in ICT Use and Associations with Declining Life Satisfaction}

Table 4 reports changes in students' ICT use between 2015 and 2018 in three subdomains (ICT use at school in general, outside of school for schoolwork and outside of school for leisure) and how these changes were associated with declining levels in LS. Results for each of the specific items included in each subdomain are detailed in Tables A3.4 to A3.7 in Appendix 3. Due to high levels of missing data in some countries (ranging from 57\% to 95\%), only France, England, Ireland and Japan were considered in the analysis (missing data levels ranging from $4 \%$ to $13 \%$ ).

\subsubsection{Levels of ICT Use across Gender and Countries}

In general, ICT use was more common among boys than among girls in the schoolrelated subdomains (i.e. at school in general and outside of school for schoolwork), and much more common among boys than among girls outside of school for leisure purposes.

\subsubsection{Changes in ICT Use between 2015 and 2018 across Gender and Countries}

Between 2015 and 2018, ICT use at school increased in France and Ireland for both girls and boys. ICT use outside of school for schoolwork increased in France, Ireland and Japan for both gender groups but declined among boys in England. ICT use outside of school for leisure increased in Japan and Ireland for both gender groups and in France and England among girls only.

\subsubsection{Association between Changes in ICT Use and Declining LS across Gender and Countries}

Changes in ICT use were associated with declining LS in only a few cases. Also, negative endowment effects were observed in a few instances. When considering overall ICT use (all three subdomains combined), a small proportion of the cohort gap in LS was related to changes in the ICT variables only for both girls and boys in England (relative endowment effects of $7.00 \%$ and $6.68 \%$, respectively) and for girls in Ireland (7.99\%). These estimates were much smaller than those observed for changes in school well-being described in Table 2.

\section{Discussion}

In the period 2015-2018, data from the PISA study show declines in adolescents' LS across a large number of countries, especially in the UK (England, Scotland, Wales and Northern Ireland), Ireland, the US, Japan and France. In these countries, 


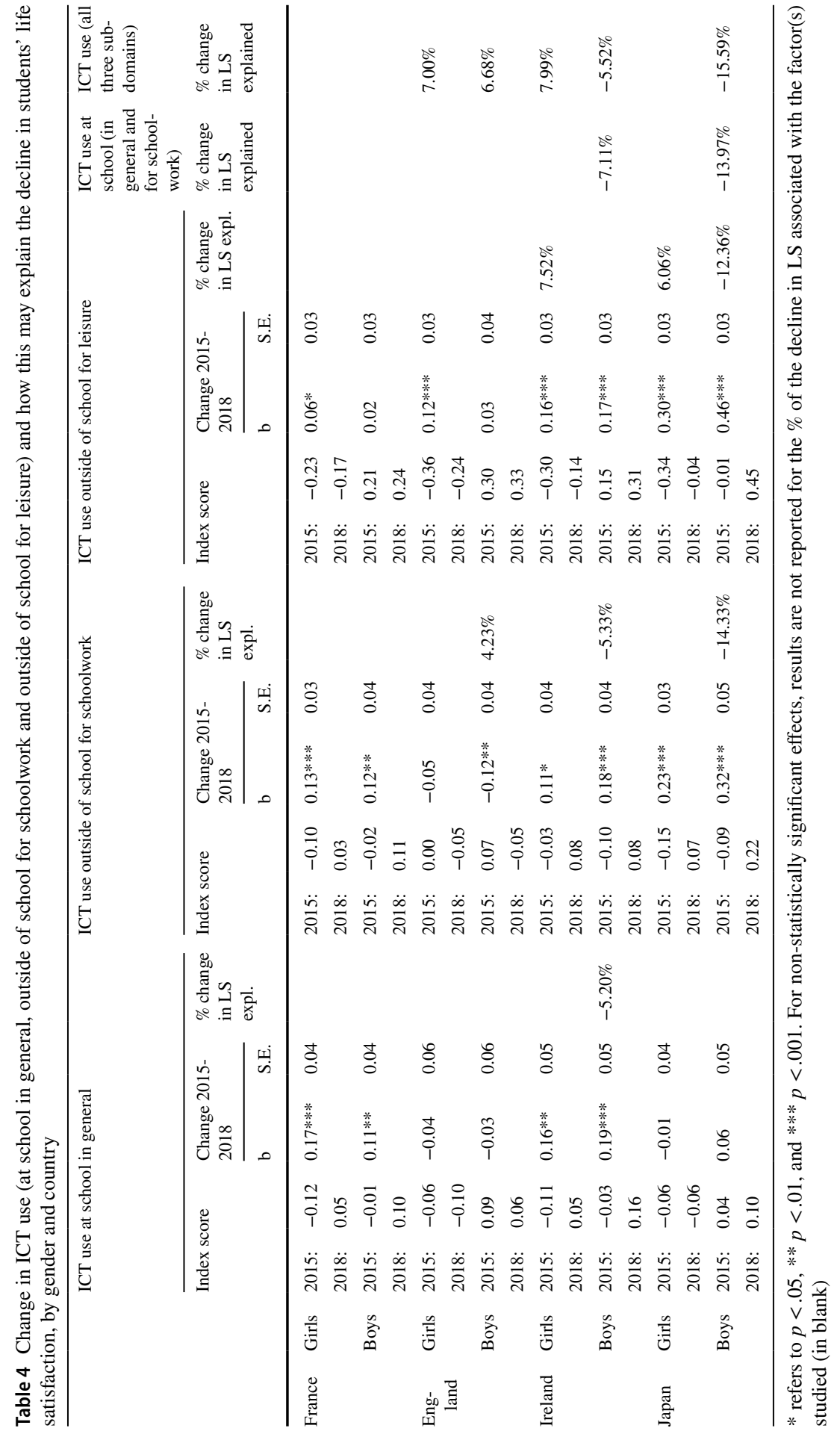


the declines in mean LS ranged between approximately 0.4 and 1 point on the 0 to 10 scale (Marquez \& Long, 2020). These findings are supported by a growing body of research indicating declining levels of subjective well-being and positive mental health among adolescents in multiple countries (e.g. Earle, 2016; Frith, 2016; The Children's Society, 2020; Twenge et al., 2017, 2018).

In order to effectively address these concerning trends, it is important to identify factors potentially explaining this phenomenon and, importantly, whether these may be similar or different across country or gender. Given the lack of international comparative research in this area, our study aimed to fill this gap. Overall, the results provided support for our hypothesis as we found that, although there are some similarities across nations, there are also substantial differences across countries -especially between the only Eastern Asian country studied (Japan) and the Western nations- as well as some gender differences in factors associated with declines in adolescents' LS in the period 2015-2018.

\subsection{Findings}

The factors studied focused on three key domains of adolescents' lives: school, digital technology and material well-being. We found that, compared to changes in material well-being and ICT use, the deterioration in school well-being was more strongly associated with declining LS in the majority of countries. The exception was Japan where school well-being was found to be far less important in relation to changes in LS. Within the school domain, despite some exceptions, declining LS was more strongly related to the deterioration in sense of belonging at school than to the deterioration of feeling emotionally supported by parents in relation to school, or to the increase in the incidence of being bullied. A more detailed look at specific items within the sense of belonging subdomain revealed that increases in the proportion of adolescents reporting feeling left out of things, out of place, or lonely at school seem especially important when it comes to understanding declining levels in LS (Table A2.1 in Appendix 2). The data suggest that feelings of social isolation and lack of social integration may be increasing (see appendix 2) within the school setting, and possibly impacting wider aspects of student wellbeing. Given the importance of school connectedness and social support in protecting against a range of negative outcomes, for example, psychosomatic symptoms and suicidal behaviours, (Marraccini \& Brier, 2017; Torsheim \& Wold, 2003), this highlights the need for schools to nurture supportive relationships and promote opportunities for engagement across different areas of school life. Likewise, tackling bullying and increasing parents' support in relation to school (Bouakaz, 2007; Park \& Holloway, 2013) are also essential to promote students' wellbeing.

Overall, in the school well-being domain, results for all the Anglo-Saxon countries studied and France are similar, and a clear divide is observed between the seven Western nations and Japan. The similarities between the Western nations studied regarding the deterioration of school well-being and its association with declining LS are interesting because some of these nations have relatively different education and social systems. Perhaps, this clear pattern could be explained by some 
mechanisms that cut across relatively different institutional and social contexts. For example, research in the UK has found increasing levels of anxiety related to future orientation, social media use, education, and normalization of mental distress and self-harm, (Bell et al., 2019). It could be hypothesised that these might result in growing levels of social and school pressure, which would ultimately impact school well-being (and sense of belonging at school and loneliness in particular), and this mechanism would be at work not only in the UK but also in these other countries. As to the divide between Western nations and Japan, it might be possible that increases in social and school pressure did not occur in the period studied or did not affect these specific aspects of school life (i.e. loneliness and sense of belonging at school). Alternatively, as discussed in the introduction, these differences may be explained by cultural considerations (Bradshaw, 2015; Leu et al., 2011; Lu \& Gilmour, 2004) that may affect how children in different socio-cultural settings respond to questions about their school well-being in school surveys. Further research is needed to explore the possible mechanisms at work in these different countries.

For material well-being and ICT use, the relationship with declining LS was less substantial and less consistent overall. In the case of material well-being, evidence of the importance of this factor was more substantial for the index of family wealth than for educational resources and cultural possessions in the household. This was observed in the UK (excluding Scotland), where the 2018 cohort reported lower material well-being (i.e. family wealth; but not lower level of educational and cultural resources) and part of the decline in LS was related to this decline. Material deprivation is strongly associated with poorer child and adolescent health outcomes (Elgar et al., 2015; Inchley et al., 2020; Torsheim et al., 2004) and there is evidence of worsening inequalities following the recent global economic recession, particularly in countries with higher levels of austerity, such as the UK (Collishaw et al., 2019; Rajmil et al., 2020). These findings are in line with those by Bell et al. (2019) concerning the importance of anxiety regarding austerity when it comes to understanding the deterioration in wellbeing and positive mental health in young people in the UK.

Finally, our study also revealed the existence of gender differences. For example, in England, the proportion of the decline in adolescents' LS related to the deterioration in sense of belonging at school was greater for boys than for girls. Previous research has shown that girls and boys have varying experiences at school and therefore may differ in how different aspects of school shape their subjective well-being (Casas \& González, 2017). Building on this, our study provided evidence of gender differences in trends in school-related factors and how these are related to declines in adolescents' LS. From a gendered perspective, we also found interesting findings in relation to ICT use, and video gaming in particular. Results reported in Table A2.4 in Appendix 2 revealed that the amount of time spent playing video games increased for both girls and boys in the four countries for whom these data were available. However, while this increase in ICT use was associated with declining levels in LS among girls, no association was found among boys. Furthermore, the opposite effect was observed in Ireland and Japan, such that increases in playing online games via social media were positively related to LS among boys. This would suggest a pattern cutting across relatively different socio-cultural contexts that, although video 
gaming is becoming increasingly popular among girls too, this is a hobby that is more beneficial for LS among boys than among girls.

\subsection{Limitations}

This study had several limitations which need to be considered in the interpretation of the results. First, it focused on a relatively short period of time, which limits longitudinal generalisations. Second, the data were from 15 to 16 year old adolescents enrolled in mainstream education in high-income countries. Findings may differ for adolescents at different stages of development or their school careers. Third, the study was based on secondary analyses of existing data and was therefore limited by the data available. Other relevant aspects of adolescents' lives, such as peer relationships or school-related anxiety were not included. Fourth, the Blinder-Oaxaca analysis reflects only the importance of the factors included in the models. As more factors are included in the models, the relevance of these in explaining the cohort gap in LS tends to decline. Thus, the importance of the factors studied may be overestimated. Fifth, the main outcome variable of the study is a single-item scale of LS, but research suggests the use of multi-item scales, particularly in cross-country studies (Casas, 2017; Casas et al., 2013; Diamantopoulos et al., 2012). This limitation is also relevant with regard to gender differences in subjective well-being, as previous research has shown that these are dependent on the instrument used (Casas \& González, 2017; Chen et al., 2019). Ideally, composite scales of LS or subjective well-being would be used, but these data were not available in both PISA 2015 and 2018. Similarly, data were not available for the other main component of subjective well-being, this is affective well-being. Previous research has shown that gender differences in affective wellbeing can be substantial during early adolescence (e.g. see Casas \& González-Carrasco, 2020). Thus, researchers should consider incorporating affective well-being data in future analyses exploring population-level declines in subjective well-being. Sixth, the Cronbach's Alpha of the material well-being subscales was below the acceptable level of 0.70 points or more and, therefore, results involving these sub-scales need to be interpreted with more caution. And finally, the PISA study is primarily intended to measure academic competence and, although other important information such as students' LS is collected, far less consideration is given to this question. More information about the properties of the LS variable and, more generally, the PISA study design and questionnaire can be found in PISA's technical report (OECD, 2017b, 2019b). However, the study is unique in providing comparative analyses across a large sample of adolescents using data collected according to a standardised protocol.

\subsection{Conclusions}

Recent reported deterioration in adolescents' subjective well-being and mental health is concerning, and action is required to counteract these trends. Our findings demonstrate the existence of some similarities -but also differences- across countries as well as some gender differences in the factors associated with declining LS. 
Evidence of cross-country differences highlights the importance of the wider social, cultural and political context in which changes in young people's lives take place. These findings are relevant from a policy perspective, as more nuanced approaches may help identify the policy and practice interventions that may be most effective in different geographical contexts, and for different groups of children and young people. Furthermore, our findings suggest that, when it comes to understanding declining LS in adolescents in recent years, school well-being is relatively more important than material well-being and ICT use in Western nations - but not in Japan. These patterns seem to be mainly driven by declines in a sense of belonging at school, thus suggesting that young people experience feelings of being disconnected from their school community. The observed trends reinforce the importance of strong and supportive relationships for adolescent wellbeing and highlight the critical role that schools can play in providing nurturing environments to support positive socio-emotional development.

Supplementary Information The online version contains supplementary material available at https://doi. org/10.1007/s12187-022-09930-8.

Acknowledgements Marquez was supported by the Economic and Social Research Council (grant number ES/V012002/1). Long was supported by the Medical Research Council (MC_UU_00022/1, MR/ S015078/1) and the Chief Scientifist Office of the Scottish Government Health and Social Care Directorate (SPHSU16). Inchley was supported by the Medical Research Council (MC_UU_00022/3) and the Chief Scientifist Office of the Scottish Government Health and Social Care Directorate (SPHSU18).

\section{Declarations}

Conflict of Interest The authors of this manuscript whose names are listed in the enclosed title page certify that they have NO affiliations with or involvement in any organization or entity with any financial or nonfinancial interest in the subject matter or materials discussed in this manuscript.

Open Access This article is licensed under a Creative Commons Attribution 4.0 International License, which permits use, sharing, adaptation, distribution and reproduction in any medium or format, as long as you give appropriate credit to the original author(s) and the source, provide a link to the Creative Commons licence, and indicate if changes were made. The images or other third party material in this article are included in the article's Creative Commons licence, unless indicated otherwise in a credit line to the material. If material is not included in the article's Creative Commons licence and your intended use is not permitted by statutory regulation or exceeds the permitted use, you will need to obtain permission directly from the copyright holder. To view a copy of this licence, visit http://creativecommons.org/licen ses/by/4.0/.

\section{References}

Arthaud-Day, M. L., Rode, J. C., Mooney, C. H., \& Near, J. P. (2005). The subjective well-being construct: A test of its convergent, discriminant, and factorial validity. Social Indicators Research, 74(3), 445-476. https://doi.org/10.1007/s11205-004-8209-6

Bell, J., Reid, M., Dyson, J., Schlosser, A., \& Alexander, T. (2019). There's just huge anxiety: Ontological security, moral panic, and the decline in young people's mental health and well-being in the UK. Qualitative Research in Medicine and Healthcare, 3(2), 87-97. https://doi.org/10.4081/qrmh.2019. 8200 
Blinder, A. (1973). Wage discrimination: Reduced form and structural estimates. The Journal of Human Resources, 8(4), 436-455. https://doi.org/10.2307/144855

Boer, M., van den Eijnden, R., Boniel-Nissim, M., Wong, S., Inchley, J., Badura, P., Craig, W. M., Gobina, I., Klesczewska, D., Klanšček, H. J., \& Stevens, G. W. J. M. (2020). Adolescents' intense and problematic social media use and their wellbeing in 29 countries. Journal of Adolescent Health, 66, 89-99. https://doi.org/10.1016/j.jadohealth.2020.02.014

Bor, W., Dean, A. J., Najman, J., \& Hayatbakhsh, R. (2014). Are child and adolescent mental health problems increasing in the 21st century? A systematic review. The Australian and New Zealand Journal of Psychiatry, 48(7), 606-616. https://doi.org/10.1177/0004867414533834

Bouakaz, L., (2007). Parental involvement in school: What promotes and what hinders parental involvement in an urban school. Malmö studies in educational sciences: Doctoral dissertation series, 30, Lärarutbildningen, Malmö högskola.

Bradley, R. H., \& Corwyn, R. F. (2004). Life satisfaction among European American, African American, Chinese American, Mexican American, and Dominican American adolescents. International Journal of Behavioral Development, 28(5), 385-400. https://doi.org/10.1080/01650250444000072

Bradshaw, J. (2015). Subjective well-being and social policy: Can nations make their children happier? Child Indicators Research, 8(1), 227-241. https://doi.org/10.1007/s12187-014-9283-1

Bradshaw, J., Crous, G., \& Turner, N. (2017). Comparing children's experiences of schools-based bullying across countries. Children and Youth Services Review. Pergamon, 80, 171-180. https://doi.org/ 10.1016/j.childyouth.2017.06.060

Brailovskaia, J., \& Margraf, J. (2020). Decrease of well-being and increase of online media use: Cohort trends in German university freshmen between 2016 and 2019. Psychiatry Research, 290, 113110, ISSN 0165-1781. https://doi.org/10.1016/j.psychres.2020.113110

Brann, E., Chaplin, J. E., Ageli, M. L., Sjöberg, A., Niklasson, A., Albertsson-Wikland, K., \& Lissner, L. (2017). Declining Well-Being in Young Swedes Born in 1990 Versus 1974. Journal of Adolescent Health, 60(3), 306-312. https://doi.org/10.1016/j.jadohealth.2016.10.009

Cantril, H. (1965). The pattern of human concerns. Rutgers University Press.

Casas, F. (2017). Analysing the comparability of 3 multi-item subjective well-being psychometric scales among 15 countries using samples of 10 and 12-year-olds. Child Indicators Research, 10, 297-330. https://doi.org/10.1007/s12187-015-9360-0

Casas, F., \& González, M. (2017). School: One world or two worlds? Children's perspectives. Children and Youth Services Review, 80(C), 157-170. https://doi.org/10.1016/j.childyouth.2017.06.054

Casas, F., \& González-Carrasco, M. (2020). The evolution of positive and negative affect in a longitudinal sample of children and adolescents. Child Indicators Research, 13, 1503-1521. https://doi.org/ 10.1007/s12187-019-09703-w

Casas, F., Sarriera, J. C., Alfaro, J., Gonzalez, M., Malo, S., Bertran, I., Figuer, C., Abs da Cruz, D., Bedin, L., Paradiso, A., Weinreich, K., \& Valdenegro, B. (2012). Testing the personal wellbeing index on 12-16 year-old adolescents in 3 different countries with 2 new items. Social Indicators Research, 105, 461-482. https://doi.org/10.1007/s11205-011-9781-1

Casas, F., Bello, A., González-Carrasco, M., \& Aligué, M. (2013). Children's subjective wellbeing measured using a composite index: What impacts Spanish first-year secondary education students' subjective well-being? Child Indicators Research, 6(3), 433-460. https://doi.org/10.1007/ s12187-013-9182-X

Casas, F., Tiliouine, H., \& Figuer, C. (2014). The subjective well-being of adolescents from two different cultures: Applying three versions of the PWI in Algeria and Spain. Social Indicators Research, 115, 637-651. https://doi.org/10.1007/s11205-012-0229-Z

Chen, X., Cai, Z., He, J., \& Fan, X. (2019). Gender differences in life satisfaction among children and adolescents: A Meta-analysis. Journal of Happiness Studies, 21, 2279-2307. https://doi.org/10. 1007/s10902-019-00169-9

Collishaw, S., Furzer, E., Thapar, A. K., \& Sellers, R. (2019). Brief report: A comparison of child mental health inequalities in three UK population cohorts. European Child and Adolescent Psychiatry, 28, 1547-1549. https://doi.org/10.1007/s00787-019-01305-9

Cosma, A., Stevens, G., Martin, G., Duinhof, E. L., Walsh, S. D., Garcia-Moya, I., Költő, A., Gobina, I., Canale, N., Catunda, C., Inchley, J., \& de Looze, M. (2020). Cross-National Time Trends in adolescent mental well-being from 2002 to 2018 and the explanatory role of schoolwork pressure. Journal of Adolescent Health, 66(6S), S50-S58. https://doi.org/10.1016/j.jadohealth.2020.02.010

Curtin, S. C., Warner, M., \& Hedegaard, H. (2016). Increase in suicide in the United States, 1999-2014. NCHS Data Brief, 241, 1-8. 
Diamantopoulos, A., Sarstedt, M., Fuchs, C., Wilczynski, P., \& Kaiser, S. (2012). Guidelines for choosing between multi-item and single-item scales for construct measurement: A predictive validity perspective. Journal of the Academy of Marketing Science, 40, 434-449. https://doi.org/10.1007/ s11747-011-0300-3

Diener, E., Lucas, R., \& Oishi, S. (2002). Subjective well-being: The science of happiness and life satisfaction. In C. R. Snyder \& S. J. Lopez (Eds.), The handbook of positive psychology (pp. 63-73). Oxford University Press.

Dinisman, T., \& Ben-Arieh, A. (2016). The characteristics of Children's subjective well-being. Social Indicators Research, 126(2), 555-569. https://doi.org/10.1007/s11205-015-0921-X

Earle, J. (2016). Children and young People's mental health. British Medical Association.

Elgar, F. J., Pförtner, T. K., Moor, I., De Clercq, B., Stevens, G. W., \& Currie, C. (2015). Socioeconomic inequalities in adolescent health 2002-2010: A time-series analysis of 34 countries participating in the health behaviour in school-aged children study. Lancet (London, England), 385(9982), 20882095. https://doi.org/10.1016/S0140-6736(14)61460-4

Etezady, A., Shaw, F. A., Mokhtarian, P. L., \& Circella, G. (2021). What drives the gap? Applying the Blinder-Oaxaca decomposition method to examine generational differences in transportationrelated attitudes. Transportation, 48, 857-883. https://doi.org/10.1007/s11116-020-10080-5

Fleming, T. M., Clark, T., Denny, S., Bullen, P., Crengle, S., Peiris-John, R., Robinson, E., Rossen, F. V., Sheridan, J., \& Lucassen, M. (2014). Stability and change in the mental health of New Zealand secondary school students 2007-2012: Results from the national adolescent health surveys. The Australian and New Zealand Journal of Psychiatry, 48(5), 472-480. https://doi.org/10.1177/00048 67413514489

Frith, E. (2016). Centre forum commission on children and young People's mental health: State of the nation. Centre Forum.

Goodwin, R. D., Weinberger, A. H., Kim, J. H., Wu, M., \& Galea, S. (2020). Trends in anxiety among adults in the United States, 2008-2018: Rapid increases among young adults. Journal of Psychiatric Research, 130, 441-446. https://doi.org/10.1016/j.jpsychires.2020.08.014

Gross-Manos, D., \& Bradshaw, J. R. (2021). The association between the material well-being and the subjective well-being of children in 35 countries. Child Indicators Research. https://doi.org/10. 1007/s12187-021-09860-x

Holstein, B. E., Damsgaard, M. T., Madsen, K. R., \& Rasmussen, M. (2020). Persistent social inequality in low life satisfaction among adolescents in Denmark 2002-2018. Children and Youth Services Review, 116, 105097. https://doi.org/10.1016/j.childyouth.2020.105097

Inchley, J., Currie, D., Budisavljevic, S., Torsheim, T., Jåstad, A., Cosma, A., Kelly, C., Arnarsson, A.M., Barnekow, V., \& Weber, M.M. (2020). Spotlight on adolescent health and well-being. Findings from the 2017/2018 Health Behaviour in School-aged Children (HBSC) survey in Europe and Canada. International report. Volume 2. Key data. WHO Regional Office for Europe.

Kim, Y., \& Hagquist, C. (2018). Trends in adolescent mental health during economic upturns and downturns: A multilevel analysis of Swedish data 1988-2008. Journal of Epidemiology and Community Health, 72(2), 101-108. https://doi.org/10.1136/jech-2017-209784

Kinderman, P., Tai, S., Pontin, E., Schwannauer, M., Jarman, I., \& Lisboa, P. (2015). Causal and mediating factors for anxiety, depression and well-being. The British Journal of Psychiatry the Journal of Mental Science, 206(6), 456-460. https://doi.org/10.1192/bjp.bp.114.147553

Klocke, A., Clair, A., \& Bradshaw, J. (2014). International variation in child subjective well-being. Child indicators research. Springer Netherlands, 7(1), 1-20. https://doi.org/10.1007/s12187-013-9213-7

Leu, J., Wang, J., \& Koo, K. (2011). Are positive emotions just as "positive" across cultures? Emotion, 11(4), 994-999. https://doi.org/10.1037/a0021332

Lu, L., \& Gilmour, R. (2004). Culture and conceptions of happiness: Individual oriented and social oriented subjective well-being. Journal of Happiness Studies: An Interdisciplinary Forum on Subjective Well-Being, 5(3), 269-291. https://doi.org/10.1007/s10902-004-8789-5

Marquez, J., \& Long, E. (2020). A global decline in adolescents' subjective well-being: A comparative study exploring patterns of change in the life satisfaction of 15-year-old students in 46 countries. Child Indicators Research, 14, 1251-1292. https://doi.org/10.1007/s12187-020-09788-8

Marquez, J., \& Main, G. (2020). Can schools and education policy make children happier? A comparative study in 33 countries. Child Indicators Research, 14, 283-339. https://doi.org/10.1007/ s12187-020-09758-0 
Marraccini, M. E., \& Brier, Z. (2017). School connectedness and suicidal thoughts and behaviors: A systematic meta-analysis. School Psychology Quarterly : the Official Journal of the Division of School Psychology, American Psychological Association, 32(1), 5-21. https://doi.org/10.1037/spq0000192

McManus, S., Gunnell, D., Cooper, C., Bebbington, P. E., Howard, L. M., Brugha, T., Jenkings, R., Hassiotis, A., Weich, S., \& Appleby, L. (2019). Prevalence of non-suicidal self-harm and service contact in England, 2000-14: Repeated cross-sectional surveys of the general population. The Lancet Psychiatry, 6(7), 573-581. https://doi.org/10.1016/S2215-0366(19)30188-9

Mercado, M. C., Holland, K., Leemis, R. W., Stone, D. M., \& Wang, J. (2017). Trends in emergency department visits for nonfatal self-inflicted injuries among youth aged 10 to 24 years in the United States, 2001-2015. The Journal of the American Medical Association, 318(19), 1931-1933. https:// doi.org/10.1001/jama.2017.13317

Metler, S. J., \& Busseri, M. A. (2017). Further evaluation of the tripartite structure of subjective wellbeing: Evidence from longitudinal and experimental studies. Journal of Personality, 85(2), 192206. https://doi.org/10.1111/jopy.12233

Mishina, K., Tiiri, E., Lempinen, L., Sillanmäki, L., Kronström, K., \& Sourander, A. (2018). Time trends of Finnish adolescents' mental health and use of alcohol and cigarettes from 1998 to 2014. European Child \& Adolescent Psychiatry, 27(12), 1633-1643. https://doi.org/10.1007/s00787-018-1158-4

Mojtabai, R., \& Olfson, M. (2020). National Trends in mental health care for US adolescents. JAMA Psychiatry, 77(7), 703-714. https://doi.org/10.1001/jamapsychiatry.2020.0279

Mojtabai, R., Olfson, M., \& Han, B. (2016). National Trends in the prevalence and treatment of depression in adolescents and young adults. Pediatrics, 138(6), e20161878. https://doi.org/10.1542/peds. 2016-1878

Oaxaca, R. (1973). Male-female wage differentials in urban labor markets. International Economic Review, 14(3), 693-709. https://doi.org/10.2307/2525981

OECD. (2017a). PISA 2015 results (volume III): Students' well-being. OECD Publishing. https://www. oecd-ilibrary.org/education/resultats-du-pisa-2015-volume-ii_9789264267558-fr. Accessed 4 Nov 2021.

OECD. (2017b). PISA 2015 technical report. OECD Publishing. https://www.oecd.org/pisa/data/2015technical-report/. Accessed 4 Nov 2021.

OECD. (2019a). PISA 2018 results (volume I): What students know and can do. OECD Publishing. https://doi.org/10.1787/5f07c754-en

OECD. (2019b). PISA 2018 technical report. OECD Publishing.https://www.oecd.org/pisa/data/2015technical-report/. Accessed 4 Nov 2021.

Park, S., \& Holloway, S. D. (2013). No parent left behind: Predicting parental involvement in Adolescents' education within a Sociodemographically diverse population. The Journal of Educational Research, 106(2), 105-119. https://doi.org/10.1080/00220671.2012.667012

Patalay, P., \& Fitzsimons, E. (2016). Correlates of mental illness and wellbeing in children: Are they the same? Results from the UK millennium cohort study. Journal of the American Academy of Child and Adolescent Psychiatry, 55(9), 771-783. https://doi.org/10.1016/j.jaac.2016.05.019

Patalay, P., \& Fitzsimons, E. (2017). Mental ill-health among children of the new century: Trends across childhood with a focus on age 14. Centre for Longitudinal Studies.

Patalay, P., \& Fitzsimons, E. (2018). Development and predictors of mental ill-health and wellbeing from childhood to adolescence. Social Psychiatry and Psychiatric Epidemiology, 53(12), 1311-1323. https://doi.org/10.1007/s00127-018-1604-0

Potrebny, T., Wiium, N., \& Lundegård, M. M. (2017). Temporal trends in adolescents' self-reported psychosomatic health complaints from 1980-2016: A systematic review and meta-analysis. PLoS One, 12(11), e0188374. https://doi.org/10.1371/journal.pone.0188374

Potrebny, T., Wiium, N., Haugstvedt, A., Sollesnes, R., Torsheim, T., Wold, B., \& Thuen, F. (2019). Health complaints among adolescents in Norway: A twenty-year perspective on trends. PLoS One, 14(1), e0210509. https://doi.org/10.1371/journal.pone.0210509

Proctor, C., Linley, P. A., \& Maltby, J. (2009). Youth life satisfaction measures: A review. The Journal of Positive Psychology, 4(2), 128-144. https://doi.org/10.1080/17439760802650816

Rajmil, L., Hjern, A., Spencer, N., Taylor-Robinson, D., Gunnlaugsson, G., \& Raat, H. (2020). Austerity policy and child health in European countries: A systematic literature review. BMC Public Health, 20(1), 564. https://doi.org/10.1186/s12889-020-08732-3

Rees, G., \& Main, G. (2015). Children's views on their lives and well-being in 15 countries: A report on the Children's Worlds survey, 2013-14. Available at: http://www.isciweb.org. Accessed 4 November 2021. 
Savahl, S., Montserrat, C., Casas, F., Adams, S., Tiliouine, H., Benninger, E., \& Jackson, K. (2019). Children's experiences of bullying victimization and the influence on their subjective well-being: A multinational comparison. Child Development, 90(2), 414-431. https://doi.org/10.1111/cdev.13135

StataCorp. (2017). Stata statistical software: Release 15. StataCorp LLC.

The Children's Society. (2020). The good childhood report 2020. The Children's Society Publications. https://doi.org/10.13140/RG.2.2.28456.80643

Torsheim, T., \& Wold, B. (2003). School-related stress, support, and subjective health complaints among early adolescents: A multilevel approach. Journal of Adolescence, 24(6), 701-713. https://doi.org/ 10.1006/jado.2001.0440

Torsheim, T., Currie, C., Boyce, W., Kalnins, I., Overpeck, M., \& Haugland, S. (2004). Material deprivation and self-rated health: A multilevel study of adolescents from 22 European and north American countries. Social Science \& Medicine (1982), 59(1), 1-12. https://doi.org/10.1016/j.socscimed. 2003.09.032

Twenge, J. M. (2020). Increases in depression, self-harm, and suicide among U.S. adolescents after 2012 and links to technology use: Possible mechanisms. Psychiatric Research and Clinical Practice, 2(1), 19-25. https://doi.org/10.1176/appi.prcp.20190015

Twenge, J. M., Joiner, T. E., Rogers, M. L., \& Martin, G. N. (2017). Increases in depressive symptoms, suicide-related outcomes, and suicide rates among U.S. adolescents after 2010 and links to increased new media screen time. Clinical Psychological Science, 6(1), 3-17. https://doi.org/10.1177/21677 02617723376

Twenge, J. M., Martin, G. N., \& Campbell, W. K. (2018). Decreases in psychological well-being among American adolescents after 2012 and links to screen time during the rise of smartphone technology. Emotion, 18(6), 765-780. https://doi.org/10.1037/emo0000403

Westerhof, G. J., \& Keyes, C. L. (2010). Mental illness and mental health: The two continua model across the lifespan. Journal of Adult Development, 17(2), 110-119. https://doi.org/10.1007/ s10804-009-9082-y

Publisher's Note Springer Nature remains neutral with regard to jurisdictional claims in published maps and institutional affiliations. 